\section{Branko Lalić \\ Gojmir Radica \\ Nikola Račić}

http://dx.doi.org/10.21278/brod67302

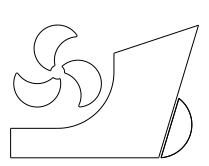

ISSN 0007-215X

eISSN 1845-5859

\title{
ANALYSIS OF EXHAUST GAS EMISSION IN THE MARINE TWO- STROKE SLOW-SPEED DIESEL ENGINE
}

\author{
UDC 629.5(05):621.436.13:665.753:536.46
}

Original scientific paper

\begin{abstract}
Summary
This paper explores the problem of exhaust emissions of the marine two-stroke slowspeed diesel engines. After establishing marine diesel engine regulations and defining the parameters influencing exhaust emissions, the simulation model of the marine two-stroke slow-speed diesel engine has been developed. Furthermore, the comparison of numerical and experimentally obtained data has been performed, resulting in achieving the model validity at $100 \%$ load, which represents a requirement for further exhaust gas analysis. Deviations obtained at the real engine and the model range from $2 \%$ to $7 \%$. An analysis of the influential parameters such as compression ratio, exhaust valve timing and fuel injection timing has been performed. The obtained results have been compared and conclusions have been drawn.
\end{abstract}

Key words: $\quad$ two-stroke slow-speed marine diesel engine; exhaust emissions; modelling

\section{Introduction}

The marine engine is an open system featuring inlet flows of air, fuel, coolant and load on the one hand, and outlet flows of exhaust gas, coolant and mechanical energy on the other. For the sake of simplicity, this study considers the marine engine as a closed system in which non-stationary gas dynamic effects have been ignored and the balance of the condition change in control volumes has been assumed. It is practically impossible to describe a diesel engine through mathematical models that would produce the same results as the real engine, but it is possible to achieve accuracy of most of the performance values within $1 \%$. The mathematical model describes the modelled object by a set of mathematical dependences that correspond to the physical characteristics of the processes and contain the familiar orientation parameters that are obtained through the evaluation or measurement of the real or physical model. The diesel engine cylinder is determined by the walls of the liner, head and piston. Mathematical modelling of the processes within the cylinder assumes that: change of gas state is in equilibrium; pressure, temperature and gas composition are identical across the entire cylinder space at all times of observation; loss of mass due to flow occur only during high pressure process stages; kinetic energy of gases in the cylinder is ignored. Our study involves this type of model [1]. 


\section{In-cylinder heat transfer}

In the cylinder of an internal combustion engine, heat is transferred to the walls mainly by convection with a contribution of radiation during combustion. The temperature field is non-stationary and non-homogeneous, resulting in differences in coefficients of heat transfer at individual points. The heat that the cylinder gases transfer to the walls is calculated for every crank angle. Three models can be used for describing heat transfer processes: Annand's, Woschni's and Eichelberg's models [2, 3, 4, 5, 6]. All of them are derived from basic reciprocities of the Reynolds and Nusselt number for flow inside circular tubes. Each model contains coefficients produced for best description of the heat transfer results achieved through experiments. In this articles, Woschni's model is used.

According to Woschni, the heat transfer by convection is defined as:

$$
h=\frac{A \cdot p^{0,8}}{D^{0,2} \cdot T^{0,55}} \cdot z^{0,8}
$$

where

$$
z=\left(B \cdot U_{p}+C \cdot U_{s}+D \cdot \frac{T_{s o c} \cdot V \cdot\left(p-p_{m}\right)}{V_{s o c} \cdot p_{s o c}}\right)
$$

where: $h$ - coefficient of the heat transfer $\left[\mathrm{W} / \mathrm{m}^{2} \mathrm{~K}\right] ; A$ - Woschni's coefficient for closed and open systems; $B$ - Woschni's coefficient for closed and open systems; $C$ - Woschni's coefficient for closed and open systems; $D$ - Woschni's coefficient for closed systems; $p$ cylinder pressure $[\mathrm{Pa}] ; T$ - cylinder temperature $[\mathrm{K}] ; V$ - cylinder volume $\left[\mathrm{m}^{3}\right] ; D$ - cylinder bore $[\mathrm{mm}] ; U_{p^{-}}$piston mean speed $[\mathrm{m} / \mathrm{s}] ; U_{s^{-}}$mean whirling velocity $[\mathrm{m} / \mathrm{s}] ; T_{s o c^{-}}$temperature of cylinder gases at the start of combustion $[\mathrm{K}] ; p_{s o c^{-}}$pressure of cylinder gases at the start of combustion $[\mathrm{Pa}] ; V_{s o c^{-}}$volume of cylinder gases at the start of combustion $\left[\mathrm{m}^{3}\right] ; p_{m^{-}}$cylinder pressure during operation $[\mathrm{Pa}]$.

The mean whirling velocity is defined as:

$$
U_{s}=\frac{N \cdot \pi \cdot D \cdot S_{r}}{30}
$$

where: $S_{r}-$ Woschni's whirl coefficient for closed and open systems;

$N$ - engine speed $\left[\mathrm{min}^{-1}\right]$.

The cylinder pressure is defined as:

$$
p_{m}=\frac{V_{s o c}^{G}}{V_{m}^{G}} \cdot p_{s o c}
$$

where: $G-$ Woschni's ratio of specific heats.

The heat flow per unit area is defined as:

$$
\frac{d \dot{Q}}{F}=h \cdot\left(T_{\text {gas }}-T_{\text {wall }}\right)
$$

As in the previous model, there are experimentally determined coefficients that depend on the way the fuel is injected into the cylinder:

- Direct-injection diesel engines: $A=3.26 ; B=4.56 ; C=0.616 ; D=0.00324 ; G=1.33$; $S r=0.0$.

- Engines featuring pre-chambers: $A=3.26 ; B=2.28 ; C=0.308 ; D=0.00324 ; G=1.33$; $S r=0.0$. 


\section{Compression and expansion}

It is assumed that during compression and expansion of the working fluid in the engine cylinder there is no leak, no working fluid exchange, and no fuel supplied to the cylinder, i.e. $d Q / d \varphi=0, d m / d \varphi=0, d \lambda / d \varphi=0$.

\subsection{Working fluid leakage through poorly sealed points}

Leaks of the working fluid may occur between the piston, piston rings and cylinder liner. Cylinder liner bore is oil lubricated in order to reduce friction during engine operation and prevent leakage of combustion gases down the sides of the piston. Lubricating oil is injected to the cylinder walls and spread across the bore of the cylinder liner, thus inhibiting the passage of the combustion gases. Slow-speed reciprocating engines are provided with the construction that enables the application of special oil for lubricating the cylinders.

\subsection{Combustion}

In diesel engines, air is compressed to achieve high temperatures that enable spontaneous ignition of the fuel injected into the cylinder. Combustion involves various physical and chemical processes, including: fuel injection, fuel atomisation and distribution throughout the combustion chamber, vaporisation of droplets, mixing of fuel spray with air, firing delay, self-ignition and combustion of the homogeneous blend, diffusion combustion and after burning. Fig. 1 shows the schematic fuel supply, injection progress and release of heat during fuel combustion in the cylinder of a high-speed diesel engine. After the start of the fuel supply at the pump, a pressure wave occurs and at the moment $\varphi_{P U}$ the fuel injection begins. The shape of injection depends on the change in the piston stroke of the high pressure pump, injector design, high-pressure pipe and relief valve. The choice of the appropriate injection shape may significantly affect the combustion stage, particularly at lower loads and in slow-speed diesel engines - even at higher loads, with the purpose of reducing the maximum combustion pressure. Fuel is injected into highly pressurised air that is heated up due to compression, reaching the temperatures higher than the temperature of the fuel selfignition. Fuel, atomised into fine spray, mixes with air and evaporation takes place at the brinks of the jet. A combustible mixture of fuel vapours and air is created, resulting in spontaneous ignition and the heat release commences. The time interval between the start of fuel injection and the start of combustion is called the ignition delay. This period consists of physical delay and chemical delay. Physical delay of ignition results from the physical process of fuel preparation (atomisation, vaporisation and mixing of air with fuel), whereas chemical delay is affected by pressure and temperature in the combustion chamber and by the type of fuel.

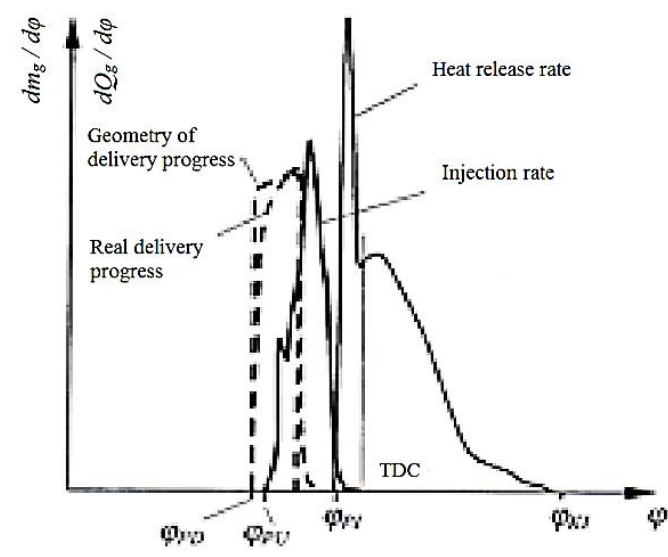

Fig. 1 Schematic description of supply at the fuel pump, injection, and heat release shape [4] 
At the start of combustion, a sudden ignition of the homogeneous mixture of air and previously vaporised fuel takes place. Combustion starts simultaneously at a number of points and progresses intensively, thus rapidly increasing the pressure and temperature (burning of the homogeneous mixture). A portion of the released heat is used for vaporisation of the remaining fuel droplets. Created vapours mix with air and engage in flame reactions (diffusion combustion), as the combustion rate is directed by the process of diffusion, mixing and turbulation of fuel and air. The cylinder pressure decreases due to ongoing expansion, while the temperature reaches its maximum.

In the last stage of combustion the rate of reactions drops with temperature that decreases during expansion. Deceleration of reaction is also induced by subsiding concentration of reaction participants. The final stage of combustions lasts approximately half the time of the total duration of combustion. Correct creation of the mixture and correct combustion result in smooth operation of the diesel engine. Good whirling motion and optimum features of the fuel injection system tend to result in a complete combustion. If mixing of air and fuel is not carried out correctly, soot is formed during diffusion combustion.

Slow-speed marine engines use heavy fuel oil compliant to ISO 8217:2010 standard, which evaporates at higher temperatures. The ignition delay time at the start of the combustion process depends on a number of parameters. Increased pressure results in increased temperature needed for vaporisation. High temperature causes rapid heat-up of oil droplets and rapid vaporisation. During chemical delay, the velocity of chemical reactions is linearly proportional to the pressure and exponentially proportional to the temperature. Higher pressure implies higher concentration of elements and higher reaction rate, i.e. shorter ignition delay. Also, the higher the temperature, the shorter the ignition delays. From the environmental standpoint, attempts are made to shorten the time of reactions in high temperature areas rich in oxygen $[7,8]$.

The diffusion stage is affected by excess air. Large amount of excess air results in easier achievement of complete combustion. Enhanced whirling motion has a favourable effect on mixture creation and combustion but also causes considerable heat loss. Subsequent injection of fuel must be avoided because it results in incomplete fuel combustion, higher exhaust temperatures and additional heat loads on the engine. The correct process of mixture creation and fuel burning provides smoother and quieter engine operation. The adequate shape of combustion space and good whirling motion of air lead to smokeless, timely and complete combustion with minimal coefficient of excess air [10]. This results in optimum engine performance during operation and convenient thermal and mechanical stresses in engine components.

Calculation of the high-pressure aspect of the process requires familiarisation with the course of achieving energy through fuel combustion. The parameters of the combustion principle can be established by means of experiments or can be approximately determined through various functions [10]. This study uses an analytic form of combustion function according to Vibe:

$$
x=\frac{Q_{f}}{\eta_{c o m} \cdot m_{f} \cdot L C V}=1-\exp \left(-C\left(\frac{\varphi-\varphi_{P I}}{\varphi_{T I}}\right)^{m+1}\right)
$$

The combustion rate is:

$$
\frac{d x}{d \varphi}=C(m+1)\left(\frac{\varphi-\varphi_{P I}}{\varphi_{T I}}\right)^{m} \exp \left(-C\left(\frac{\varphi-\varphi_{P I}}{\varphi_{T I}}\right)^{m+1}\right)
$$


where $C=6.901$ (for $99.9 \%$ of fuel combustion).

The Equation (9) implies that the release of heat is carried out in line with an exponential function, where the exponent $m$ (parameter of shape) determines the point of the highest intensity of heat release. The degree of performance $\eta_{c o m}$ takes into consideration the losses due to incomplete burning of fuel. Vibe exponent $m$ depends on operational engine parameters, ignition delay, working fluid mass and engine speed.

The so-called double Vibe function provides a more precise description of the combustion process in a diesel engine featuring direct injection, high rate of homogeneous blend and relatively slow diffusion combustion. In modelling the approximate combustion values by means of a double Vibe function, the entire combustion process is divided into two stages. The sum of both stages represents the entire course of combustion:

$$
x=x_{1}(\varphi)+x_{2}(\varphi)
$$

where

$$
\begin{aligned}
& x_{1}(\varphi)=1-\exp \left(-C\left(\frac{\varphi-\varphi_{P I}}{\varphi_{T I}}\right)^{m_{1}+1}\right) \\
& x_{2}(\varphi)=1-\exp \left(-C\left(\frac{\varphi-\varphi_{P I}}{\varphi_{T I}}\right)^{m_{2}+1}\right)
\end{aligned}
$$

The start of combustion depends on the start of fuel delivery by the high-pressure fuel pump, the delay of the fuel injection commencement and on ignition delay. At the transient regime of operation of the propulsion engine caused by increased default engine speed or increased load moment, the fuel regulation system delivers a larger amount of fuel. This results in the increased fuel/air ratio so that the amount of excess air could be actually insufficient for the burning of fuel. This phenomenon leads to incomplete combustion, soot formation and reduced output. These effects can be decreased because the regulation system is provided with a function of limiting the fuel index in accordance with the available amount of air. The latter is determined on the basis of scavenge air pressure. Incomplete combustion and soot formation are also affected by other factors, including technical features, temperature, etc. In the observed model, the fuel burning rate is determined by the heat release principle. There is no heat transfer of the working fluid to the environment during combustion.

\section{Working fluid transfer}

The concentration of burnt fuel in inlet and exhaust gases depends on the scavenge mode. Boundary cases of scavenging include complete mixing, complete expelling and combined scavenging. It can be assumed that the actual scavenging process is carried out in one of the three boundary modes or through a combination of the modes. When describing the model for cylinder scavenging, the following features are introduced:

- supply rate $\Lambda$ compares the actual mass of scavenge air with the one required by an ideal turbocharging process. The reference mass is defined as the product of the swept volume and density of turbocharged air. For the purpose of an analytic calculation, it is suitable to use the mass of air retained in the cylinder $m_{t r}$ as the reference mass.

$$
\Lambda=\frac{\text { mass of } \text { ch arg ing one process with fresh air }}{\text { reference mass }}=\frac{m_{s c}}{m^{\prime}}
$$


- efficiency of retaining air in the cylinder $\eta_{t r}$ defines how much of the air charged into the cylinder is retained there.

$$
\eta_{t r}=\frac{\text { mass of charged air retained in the cylinder }}{\text { mass of charged air supplied per process }}=\frac{m_{a r}}{m_{s c}}
$$

- scavenge efficiency $\eta_{s c}$, defines to what extent the exhaust gases are replaced by fresh air in the cylinder. For some authors, scavenge efficiency is charging cleanliness which is equal to 1 in an ideal process.

$$
\eta_{s c}=\frac{\text { mass of charged air retained in the cylinder }}{\text { total mass }(\text { air }+ \text { remaining gases })}=\frac{m_{a r}}{m_{a r}+m_{r}}
$$

- turbocharging efficiency $\eta_{c h}$, defines how efficiently the cylinder volume is filled with fresh air.

$$
\eta_{c h}=\frac{\text { mass of charged air retained in the cylinder }}{\text { reference mass }}=\frac{m_{a r}}{m^{\prime}}
$$

The relation among turbocharging efficiency, efficiency of retaining air in the cylinder and supply rate is defined by the expression:

$$
\eta_{c h}=\Lambda \cdot \eta_{t r}
$$

\subsection{Model of complete mixing}

In this model it is assumed that, at a certain point of time, the mass of air that enters the cylinder instantly and completely mixes with combustion gases within the cylinder volume. The same amount of fluids having the same shares of air and combustion gases leaves the cylinder.

\subsection{Model of complete expelling}

The model of complete expelling is the simplest model for the process of cylinder scavenging. According to the model, fresh air enters the cylinder and expels the remaining retained combustion gases toward the exhaust valve. The model of complete expelling implies the validity of expressions:

$$
\begin{aligned}
& \eta_{s c}=\Lambda \quad \text { and } \quad \eta_{t r}=1 \quad \text { for } \quad \Lambda \leq 1 \\
& \eta_{s c}=1 \quad \text { and } \quad \eta_{t r}=\Lambda^{-1} \quad \text { for } \quad \Lambda \geq 1
\end{aligned}
$$

\subsection{Model of combined scavenging}

Benson [3] and Brandhaim have suggested the model of combined scavenging - a model that combines mixing and expelling. In this model, the cylinder is divided into two areas: the area of expelling and the area of mixing. It is assumed that fresh air enters the cylinder and mixes with gases as they leave the cylinder. The cylinder volume is $V$, while $x$ is the part of the cylinder volume that is being scavenged according to the model of expelling. After the expelling process, when $x$ becomes zero, the scavenging process resumes in line with the model of mixing, see Fig. 2. Value $V_{a}$ represents the volume of the air supplied.

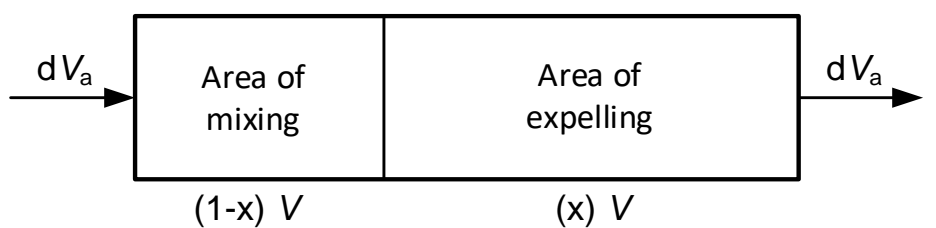

Fig. 2 Model of combined scavenging 
During the scavenging process in the slow-speed marine engines fitted with exhaust valves, a portion of fresh air can leave the cylinder directly through the exhaust valve (short circuit), and the supply rate is proportionally decreased.

\section{Exhaust gas and scavenge air receivers}

Quasi-stationary model is applied for calculating the values of the scavenge air and exhaust gas receivers, i.e. only the pressure variation in a period of time is taken into account, excluding the variation with regard to the length of the receiver. In this way it is possible to describe the process within the receiver using a set of ordinary non-linear differential equations instead of using a set of partial differential equations. The process within the receivers is similar to the one in engine cylinders. Normally, as a rule, no combustion and no work take place in the receivers because their volume is constant.

\subsection{Heat transfer in scavenge air and exhaust gas receivers}

Convective heat transfer from the gases to the walls takes place in the receivers. The calculation of heat transfer is similar to that of heat transfer in the cylinder. Correlations of the Nusselt, Reynolds and Prandtl numbers for turbulent flow are taken into consideration.

$$
N u=0,023 \cdot \operatorname{Re}^{0,8} \cdot \operatorname{Pr}^{0,4}
$$

where

$$
\begin{aligned}
& N u=\frac{h \cdot d}{k} \\
& \operatorname{Pr}=\frac{\mu \cdot c_{p}}{k} \\
& \operatorname{Re}=\frac{\rho \cdot v \cdot d}{\mu}
\end{aligned}
$$

where: $h$ - coefficient of the heat transfer $\left[\mathrm{W} / \mathrm{m}^{2} \mathrm{~K}\right] ; k$ - coefficient of the conductive gas heat transfer $[\mathrm{W} / \mathrm{mK}] ; c_{p^{-}}$specific thermal capacity $[\mathrm{kJ} / \mathrm{kgK}] ; \rho$ - gas density $\left[\mathrm{kg} / \mathrm{m}^{3}\right] ; v$ - gas flow rate $[\mathrm{m} / \mathrm{s}] ; d$ - characteristic length $[\mathrm{m}] ; \mu$-dynamic viscosity $\left[\mathrm{kgm}^{-1} \mathrm{~s}^{-1}\right]$. If the Equation (16) is arranged and the Prandtl number assumed as constant $(\operatorname{Pr}=0.71)$, the result is:

$$
h=0,02 \cdot \operatorname{Re}^{0,8} \cdot \frac{k}{d}
$$

\subsection{Turbocharger}

Radial blower and axial turbine are applied in the turbocharging systems in slow-speed two-stroke marine engines. A turbocharger is selected from the existing turbochargers produced by various manufacturers. When modelling the processes in turbochargers during engine operation, it is necessary to determine the flow and operation stages. In case of nonstationary mode of engine operation, it is also necessary to know the turbocharger's inertia moment. The turbocharger and the engine are connected by means of gases, which implies that the transmission ratio between crankshaft rotation and turbo-blower rotor cannot be defined; instead, the speed is determined by the balance between the difference of the turbine moments and the blower. Fig. 3 shows physical values that determine the operation of the turbine and the blower. 
Branko Lalić, Gojmir Radica, Nikola Račić
Analysis of exhaust gas emission in the marine two-stroke slow-speed diesel engine

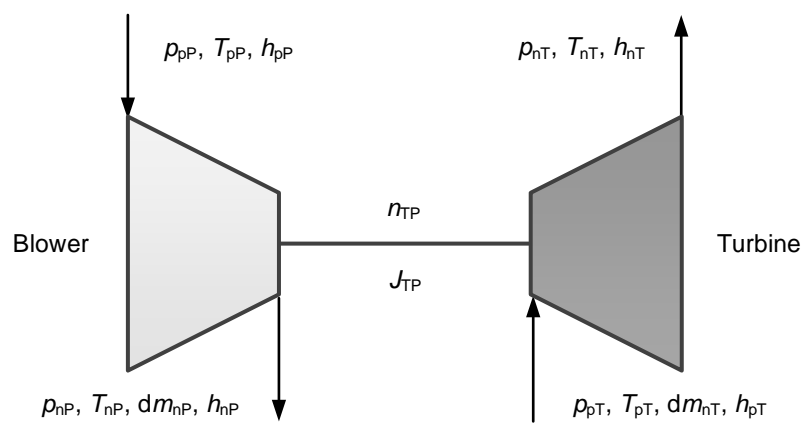

Fig. 3 Turbocharger

\subsection{Blower}

In order to complete the model for a turbocharged diesel engine, it is necessary to be familiar with the blower characteristics, i.e. with the dependence of the air flow through the blower and the efficiency in the function of the ratio between pressures and rotation speeds. Fig. 4 presents the field of the blower characteristics.

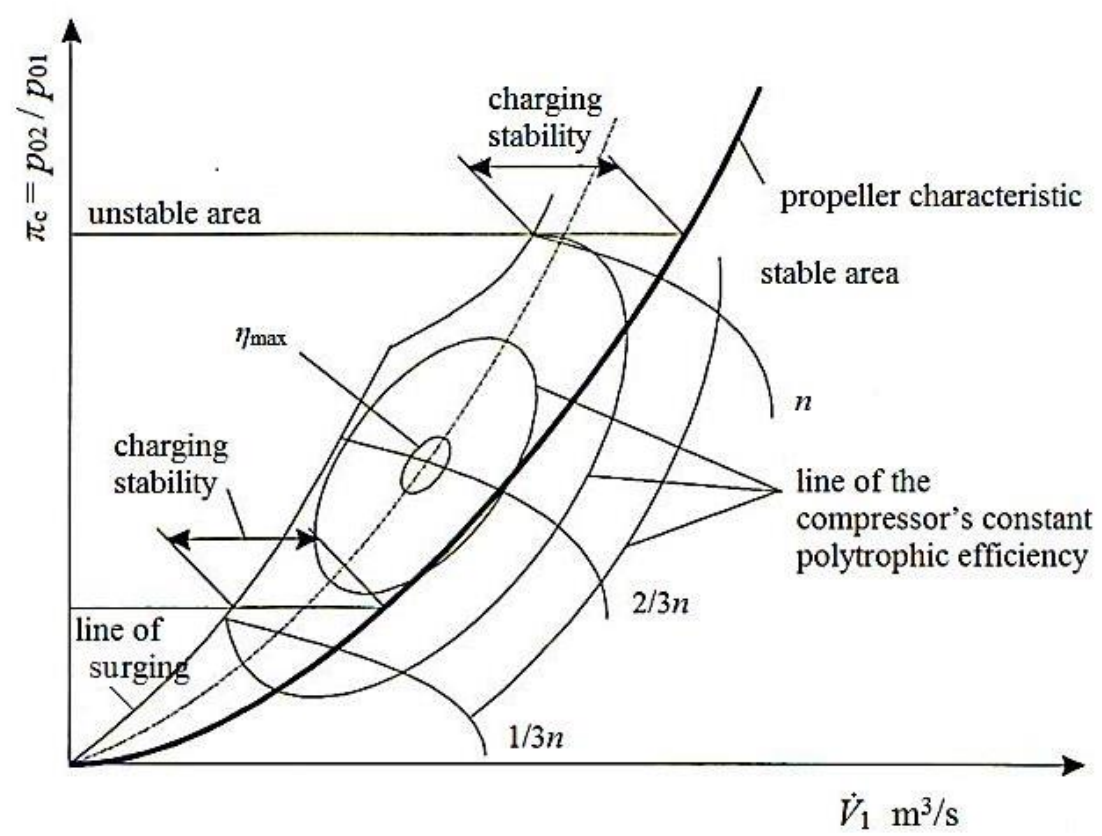

Fig. 4 Field of characteristics of the radial blower [11]

It is rather difficult to obtain an analytic form of blower features from the manufacturers of turbochargers. Therefore, it is necessary to perform an approximate valuation of the above characteristics. Needed features of a specific blower can be determined by the field of the blower features.

\subsection{Turbine}

Turbine characteristics have to be defined as a set of constant lines of rotation speed which determine the mass flow, pressure ratio and efficiency. Every rotation speed has to contain the same number of points of mass flows for each curve and has to progress monotonously. Fig. 5 shows the three-dimensional feature of the turbocharger's turbine manufactured by ABB Turbocharging Company in a large slow-speed two-stroke engine. 


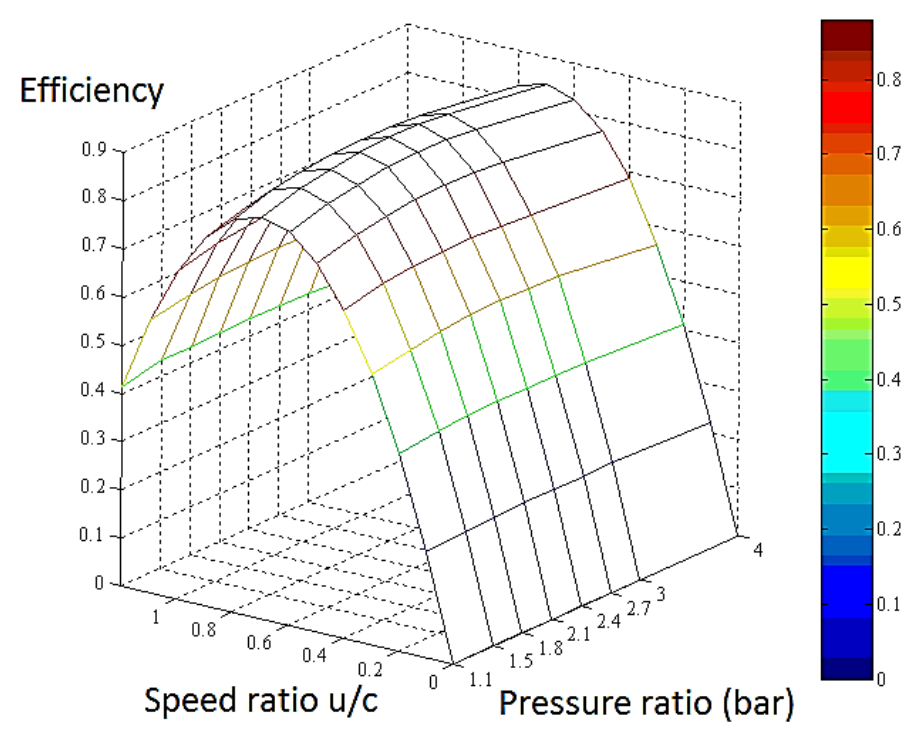

Fig. 5 Three-dimensional feature of the turbocharger's turbine [11]

\subsubsection{Dynamics of the turbocharger rotor}

The turbine and the blower are fitted to the same shaft and are connected with the engine via the gas line. In non-stationary operation mode there is a difference in moments between the turbine and the compressor, resulting in the rotor's acceleration or deceleration. The change of speed is defined by the difference of turning moments and inertia moments:

$$
\frac{d n_{T P}}{d t} \frac{d t}{d \varphi}=\frac{M_{T}-M_{P}}{J_{T P}} \cdot \frac{60}{2 \cdot \pi} \cdot \frac{d t}{d \varphi}=\frac{M_{T}-M_{P}}{J_{T P}} \cdot \frac{30}{\pi}
$$

\section{Application and analysis of the model}

This chapter deals with the application of the engine simulation model as described in previous sections. It should be noted that the analysis will include two engines with identical performance but different regarding their rotation speed and compression rate. Therefore, the calculation of emission's mass will be expressed as:

$$
m=P \cdot \frac{1}{60 \cdot n} \cdot b_{e}
$$

where: $m$ - mass of exhaust gas $[\mathrm{kg}] ; P$ - effective power $[\mathrm{kW}] ; n$ - engine speed $\left[\mathrm{min}^{-1}\right] ; b_{e^{-}}$ specific emission's mass $[\mathrm{g} / \mathrm{kWh}$.

\subsection{Deviations of the obtained values}

The simulation has been performed for the specific engine at $100 \%$ load. Deviations of the (most important) values that have been obtained through the simulation from the real values obtained at the testbed are shown in Tables 1 and 2.

Table 1 Characteristics obtained through the simulation model

\begin{tabular}{|l|c|}
\hline Engine load (MCR) & $100 \%$ \\
\hline Engine speed, min $^{-1}$ & 121 \\
\hline Effective power (kW) & 8406 \\
\hline Specific effective fuel consumption (g/kWh) & 168.66 \\
\hline Mean effective pressure (bar) & 18,52 \\
\hline Maximum cylinder pressure (bar) & 158 \\
\hline
\end{tabular}


Table 2 Deviations of the values obtained by simulation and by measuring real engine performance

\begin{tabular}{|l|c|}
\hline Engine load (MCR) & $100 \%$ \\
\hline Engine speed, $\mathrm{min}^{-1}$ & 121 \\
\hline Effective power & $2,29 \%$ \\
\hline Specific effective fuel consumption & $1,55 \%$ \\
\hline Mean effective pressure & $2,26 \%$ \\
\hline Maximum cylinder pressure & $2,53 \%$ \\
\hline
\end{tabular}

When observing Table 2, it can be noted that the deviations of the values obtained through simulation and through measuring real engine performance are minimal, which confirms the applicability of the model. The model's validity at stationary operating points is the essential prerequisite for the overall model's validity that is needed for accurate prediction of phenomena under dynamic conditions of diesel engine operation.

\section{Influence of compression rate on exhaust emissions}

As it has been already pointed out, the analysis includes two engines having identical performance but different rotation speeds and compression rates. In order to avoid repetition, the following terms will be used:

- Engine 1; real compression rate 17.2, engine speed $121 \mathrm{~min}^{-1}$;

- Engine 2; real compression rate 15.7, engine speed $110 \mathrm{~min}^{-1}$.

Table 3 Contents of exhaust gases obtained at the testbed

\begin{tabular}{|l|c|c|c|}
\hline Specific emission's mass $(\mathrm{g} / \mathrm{kWh})$ & $\mathrm{CO}_{2}$ & $\mathrm{CO}$ & $\mathrm{O}_{2}$ \\
\hline Engine 1 & 543 & 0,40 & 1340 \\
\hline Engine 2 & 521 & 0,72 & 1241 \\
\hline
\end{tabular}

\subsection{Engine 1}

The graphs referring to the values of carbon monoxide and carbon dioxide show that the simulation has been performed for four cycles and that the curves in all cycles are identical, except for the first cycle. This can be explained by the fact that the simulation starts from the point of combustion, which can be noticed by observing the values of the graph ordinate. The simulation carried out for this engine results in the following graphs:

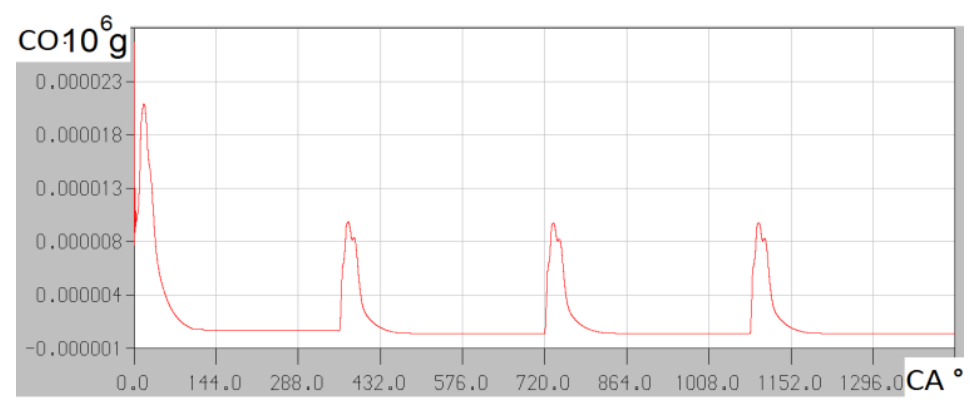

Fig. 6 Carbon monoxide depending on the crank angle

The maximum value of exhaust gases is achieved at the beginning of the first cycle, at $0^{\circ}$ crank angle. Between $0^{\circ}$ and $5^{\circ}$ of the crank angle step changes occur (Fig. 6) and start to increase after $5^{\circ}$ of the crank angle until the second peak value (Fig. 11), at about $17^{\circ}$ of the crank angle. In the remaining three cycles, the drop of the peak value is followed by a mild step increase between $382^{\circ}$ and $388^{\circ}$ of the crank angle (Fig. 10). 


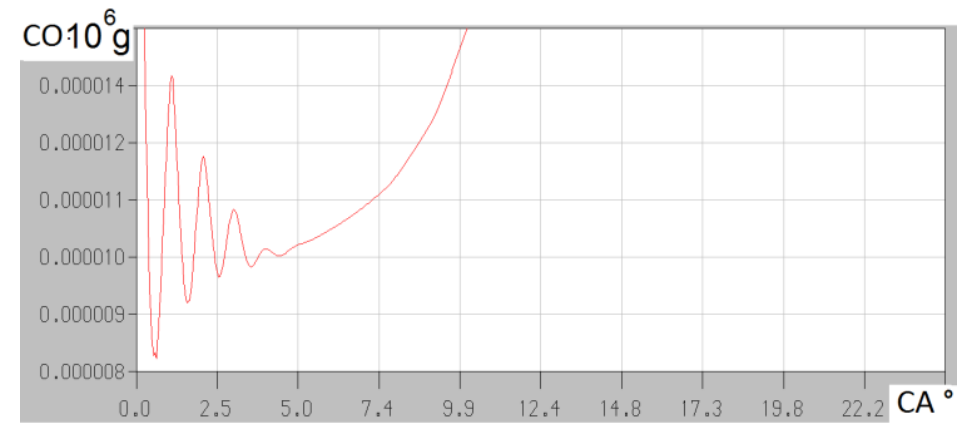

Fig. 7 Changes in $\mathrm{CO}$ values at the start of the first working cycle

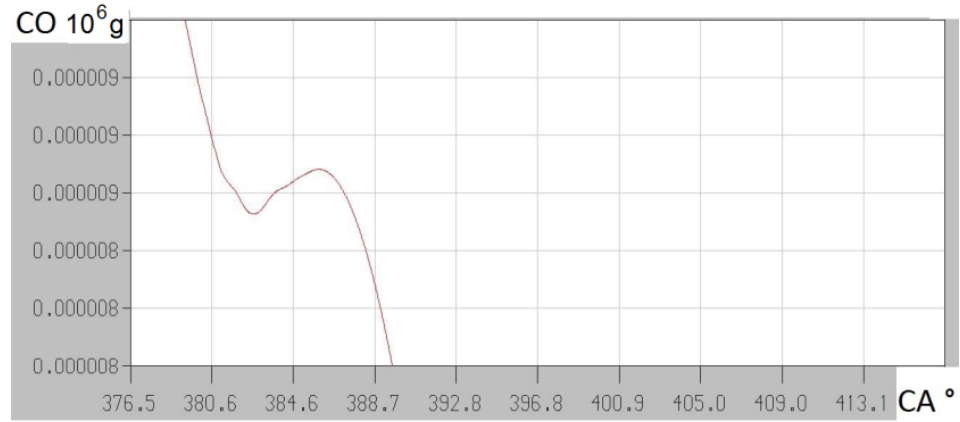

Fig 8 Changes in $\mathrm{CO}$ values at the interval between $382^{\circ}$ and $388^{\circ}$ of the crank angle

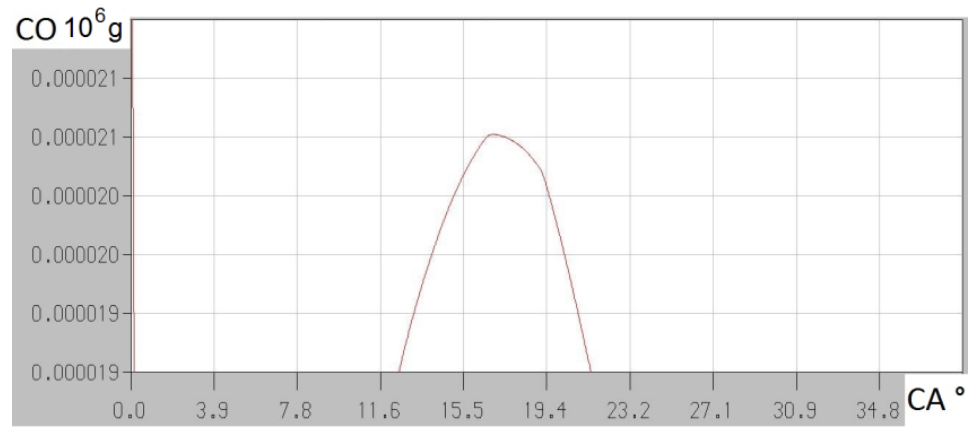

Fig. 9 Peak value of $\mathrm{CO}$ at the interval $12^{\circ}-22^{\circ}$

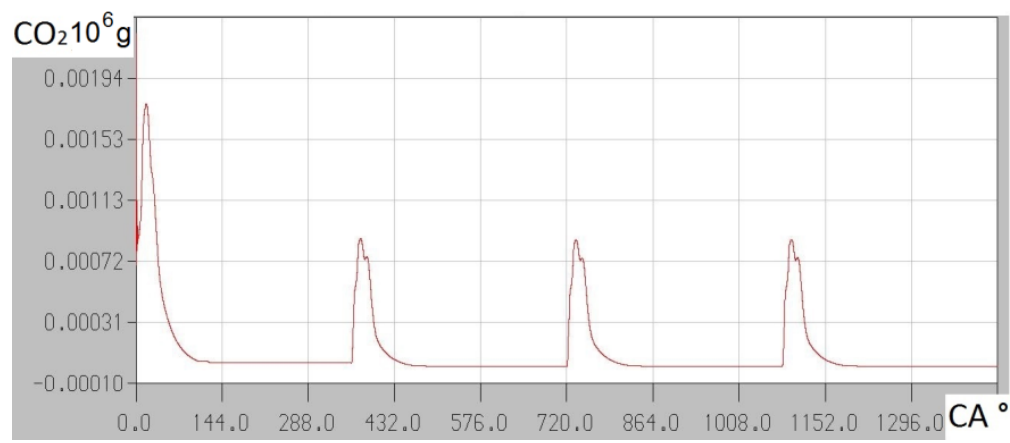

Fig. 10 Values of carbon dioxide

The carbon dioxide curve (Fig. 10) is identical to the curve of carbon monoxide. The difference lies in the fact that the characteristic changes take place at other crank angles. In the first working cycle, from $0^{\circ}$ to $3^{\circ}$ of the crank angle (Fig. 11) there are step changes in mass, which become stable not earlier than at about $6^{\circ}$ when they start to increase up to their second peak value at around $16.6^{\circ}$ of the crank angle (Fig. 12). In the remaining three cycles, after achieving the peak value, there is a mild step between $382^{\circ}$ and $386^{\circ}$ of the crank angle (see Fig. 13). 


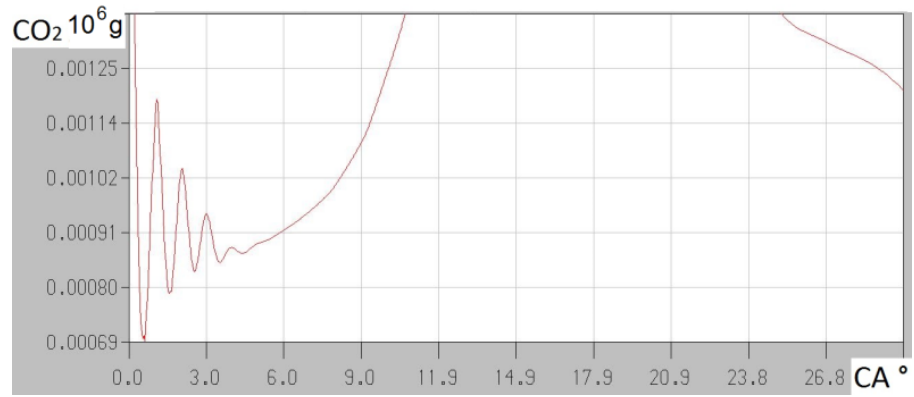

Fig. 11 Changes in $\mathrm{CO}_{2}$ at the start of the first cycle

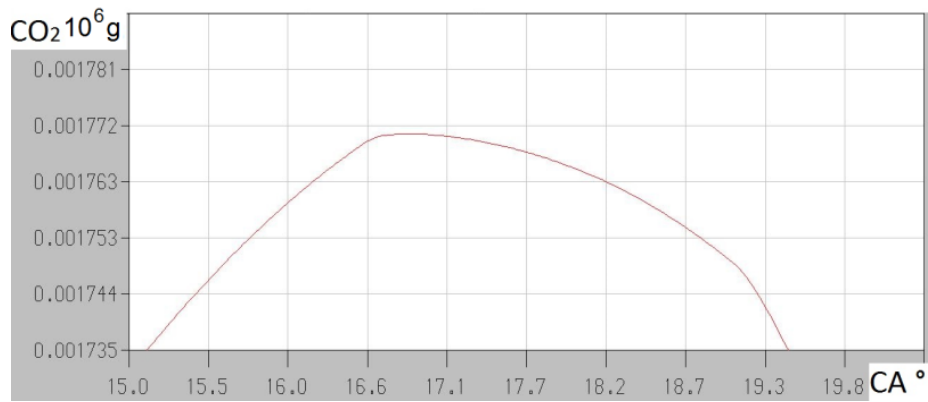

Fig. 12 Peak value of $\mathrm{CO}_{2}$ at $16.6^{\circ}$ of the crank angle in the first working cycle

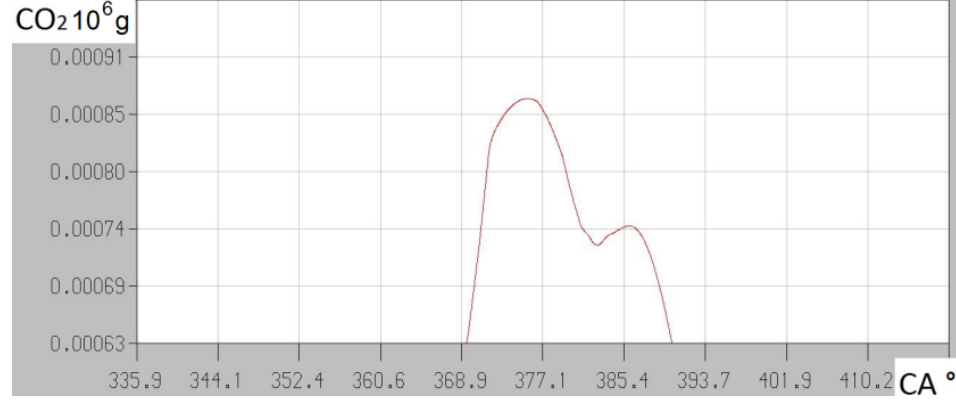

Fig. 13 Changes in $\mathrm{CO}_{2}$ at the interval $382^{\circ}-386^{\circ}$

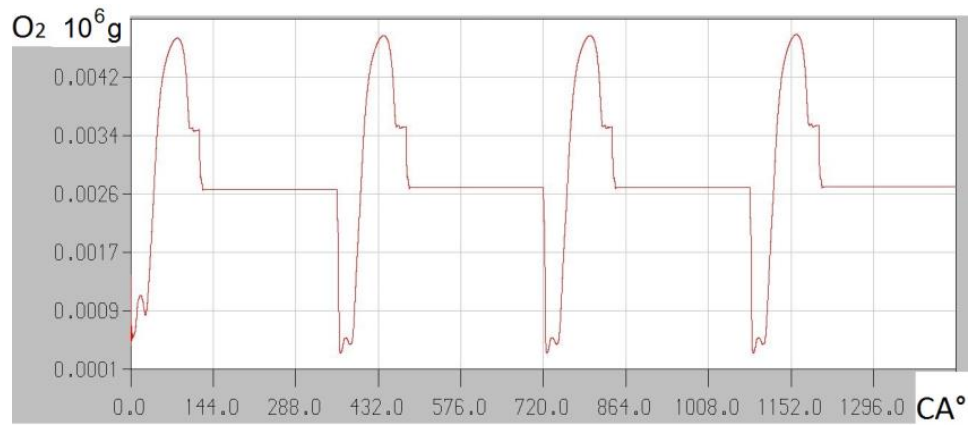

Fig. 14 Change of the amount of oxygen according to the crank angle function

Unlike the curves describing the values of carbon monoxide and carbon dioxide, the oxygen curve (Fig. 14) is identical in all four simulations, except at the very start, between $0^{\circ}$ and $4^{\circ}$ of the crank angle, when step changes occur (see Fig. 15). 


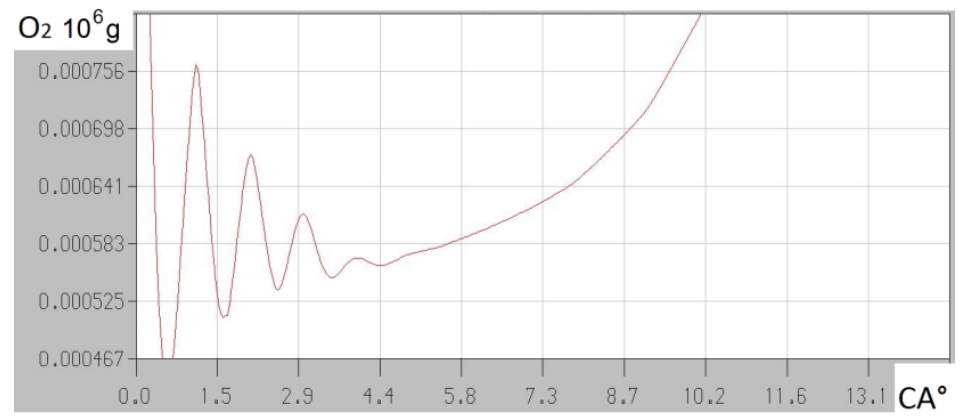

Fig. 15 Changes in the amount of $\mathrm{O}_{2}$ at the start of the cycle

The same phenomenon, although with less frequent changes, takes place between $16^{\circ}$ and $25^{\circ}$ (Fig. 16), after which the peak value is achieved (see Fig. 17).

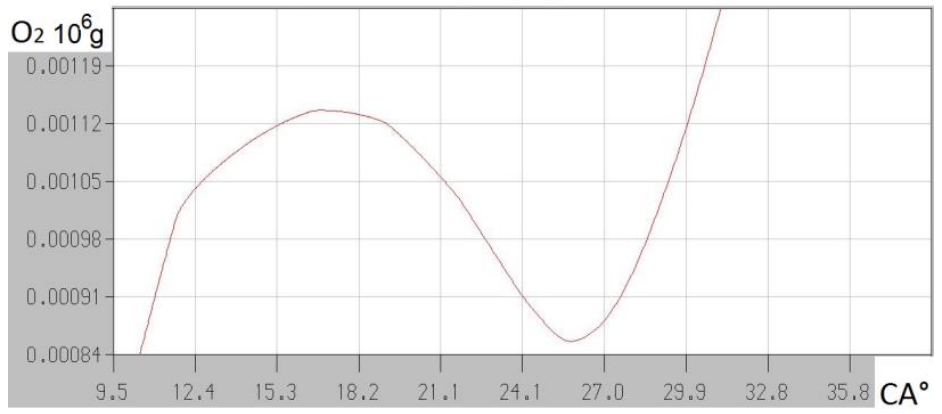

Fig. 16 Changes in $\mathrm{O}_{2}$ between $16^{\circ}$ and $25^{\circ}$ of the crank angle

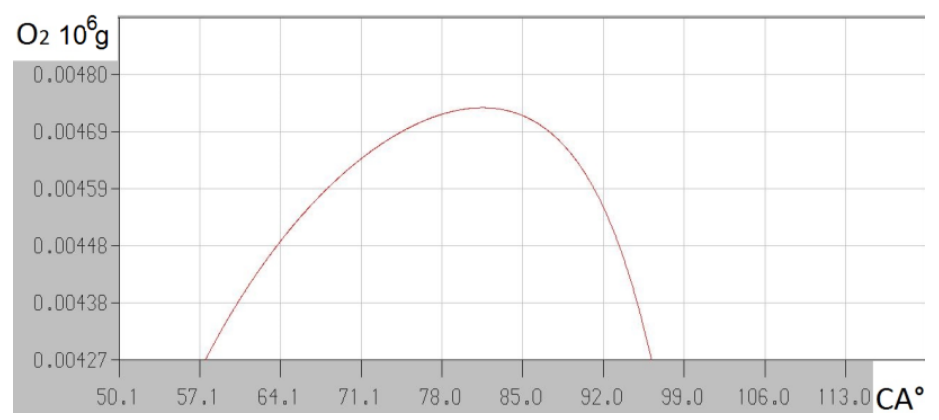

Fig. 17 Peak value in the first working cycle

At some point between $103^{\circ}$ and $120^{\circ}$ of the crank angle, step changes occur again, as shown in Figure 18.

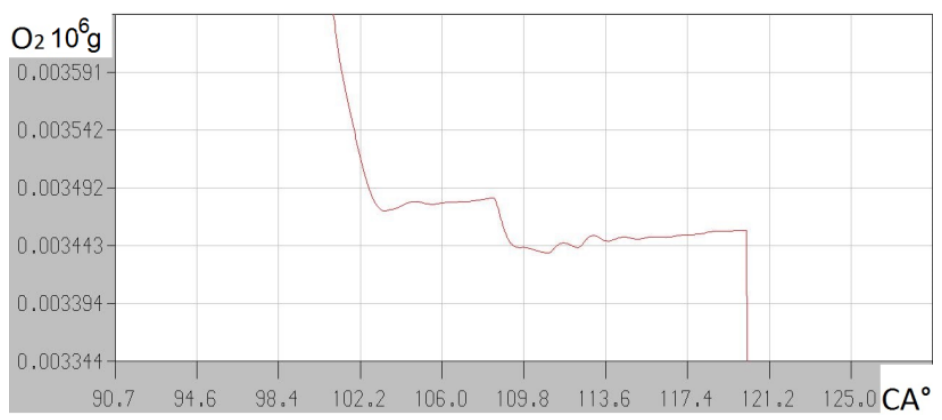

Fig. 18 Values of $\mathrm{O}_{2}$ between $103^{\circ}$ and $120^{\circ}$ of the crank angle 


\subsection{Engine 2}

The curves referring to Engine 2 describe the same values as in Engine 1, but there is a difference in peak values in the ordinate, while the points at which step changes occur take place within the boundary limits as in the previously observed engine.

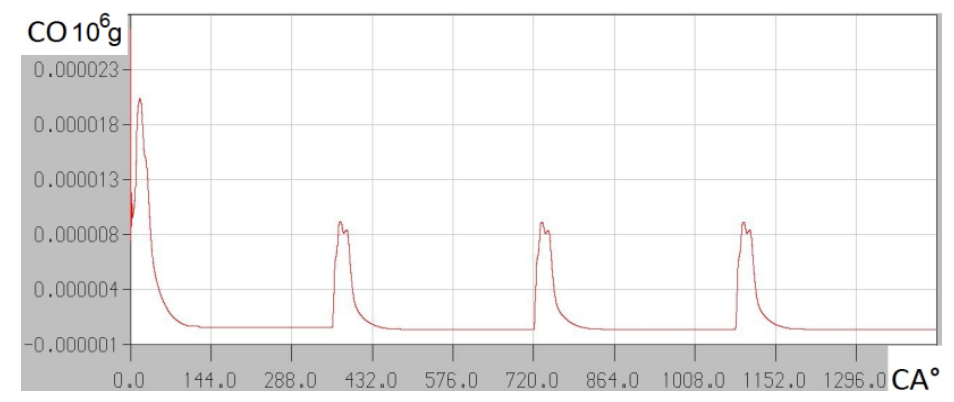

Fig 19 Values of carbon monoxide

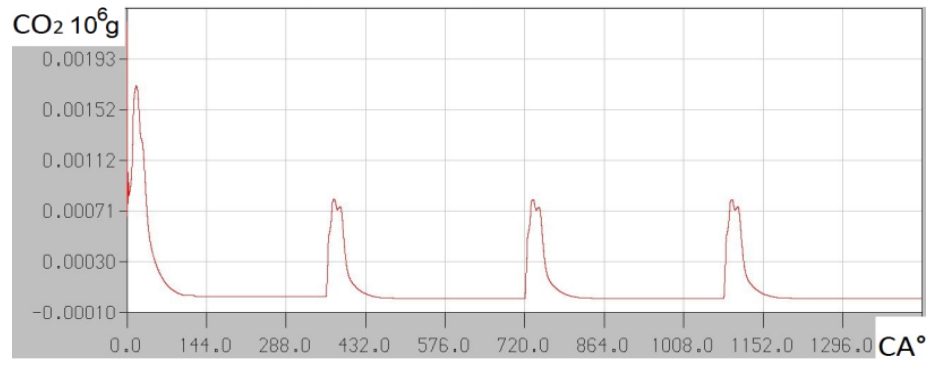

Fig. 20 Values of carbon dioxide

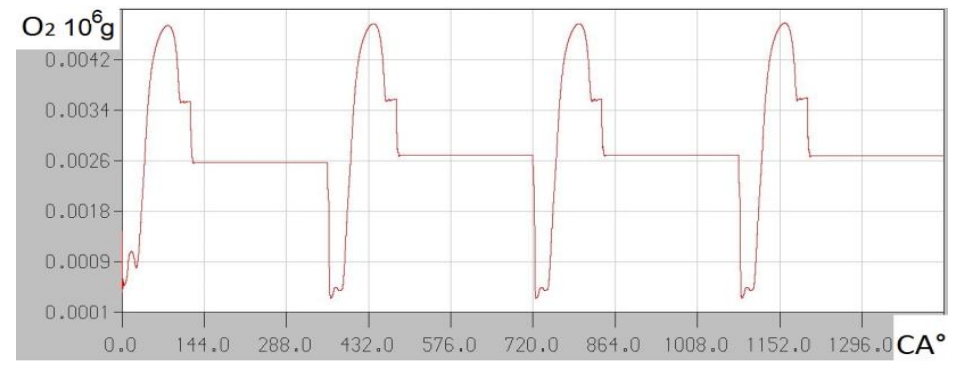

Fig. 21 Values of oxygen

7.3 Comparison of the results

When analyzing maximum values in the curves and taking into consideration that the difference in the compression ratio amounts to 1.5 , the following results are produced:

- Deviations in carbon monoxide between Engine 1 and Engine 2 amount to $0.5 \%$ in the first cycle and $1 \%$ in the remaining working cycles.

- Deviations in carbon dioxide in Engine 1 amount to $1.3 \%$ in the first cycle and $7.11 \%$ in the remaining working cycles, when compared to Engine 2.

- Deviations in oxygen in Engine 1 amount to $1.27 \%$ when compared to Engine 2.

\section{Influence of the start of combustion on exhaust emissions}

It should be noted that the simulations for the combustion angle of $0^{\circ}$ are avoided as this angle has been previously used for achieving the model's validity. Negative values of the combustion angles imply that combustion starts after the top dead centre (TDC). The shape and typical points of the curves are the same as in the curves describing variations in the compression ratio. Due to numerous combustion angles they require considerable space. Therefore, they are left out in this chapter. 


\subsection{Engine 1} values:

Changes in the crank angles for the start of combustion have produced the following

Table 4 Values achieved in Engine 1 during variations of the start of combustion

\begin{tabular}{|l|c|c|c|c|c|}
\hline Start of combustion $\left({ }^{\circ}\right.$ crank angle) & -1 & $-0,5$ & 0 & 0,5 & 1 \\
\hline Effective power $(\mathrm{kW})$ & 1393,46 & 1397,33 & 1400,96 & 1404,35 & 1407,51 \\
\hline Mean effective pressure (bar) & 18,42 & 18,48 & 18,52 & 18,57 & 18,61 \\
\hline Specific effective consumption (g/kWh) & 169,56 & 169,09 & 168,66 & 168,25 & 167,87 \\
\hline Maximum cylinder pressure (bar) & 153 & 155 & 158 & 161 & 164 \\
\hline
\end{tabular}

Table 4 shows that changes in the crank angle for the start of combustion result in the growth of parameters such as Effective strength, Mean effective pressure and Maximum cylinder pressure, whereas Specific effective consumption practically remains the same, i.e. within the limits of the values obtained when achieving the validity of the model. Deviations of these parameters during variations in the combustion angle are shown in Table 5:

Table 5 Deviations of the parameters in Engine 1 during variations of the combustion start angle

\begin{tabular}{|l|c|c|c|c|}
\hline Start of combustion $\left({ }^{\circ}\right.$ crank angle) & -1 & $-0,5$ & 0,5 & 1 \\
\hline Effective power $(\mathrm{kW})$ & $2,81 \%$ & $2,54 \%$ & $2,05 \%$ & $1,83 \%$ \\
\hline Mean effective pressure (bar) & $1,73 \%$ & $2,05 \%$ & $2,53 \%$ & $2,74 \%$ \\
\hline Maximum cylinder pressure (bar) & $0,5 \%$ & $0,7 \%$ & $4,47 \%$ & $6,21 \%$ \\
\hline
\end{tabular}

When the correlations of the combustion start angle and maximum pressures in the cylinder are shown in a diagrammatic way, a linear dependence can be noted:

Engine 1

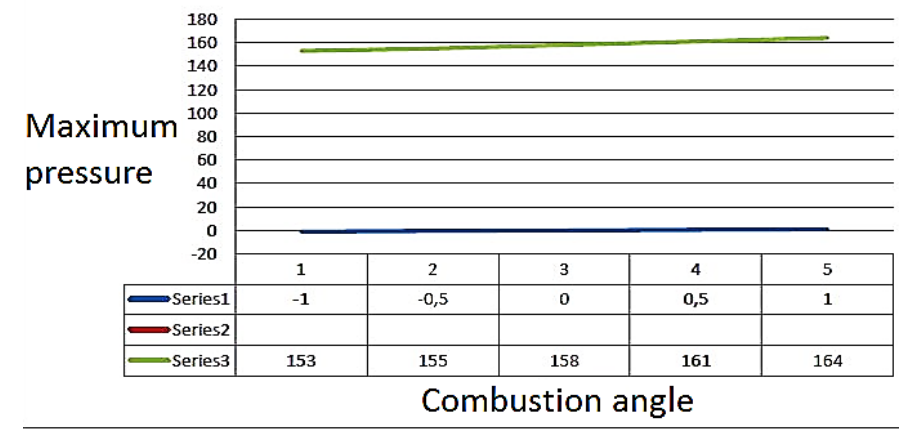

Fig. 22 Dependence of the combustion start angle (Series 1) and maximum cylinder pressures (Series 3)

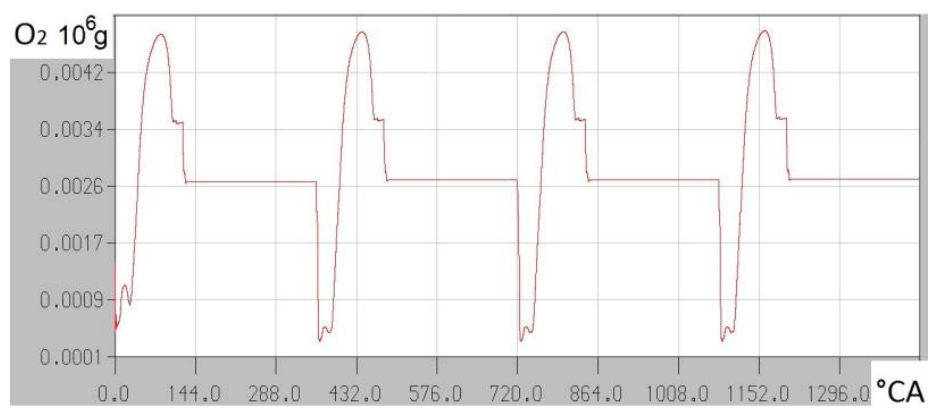

Fig. 23 Change in the amount of oxygen at the variation of the combustion start crank angle of $-0.5^{\circ}$ 


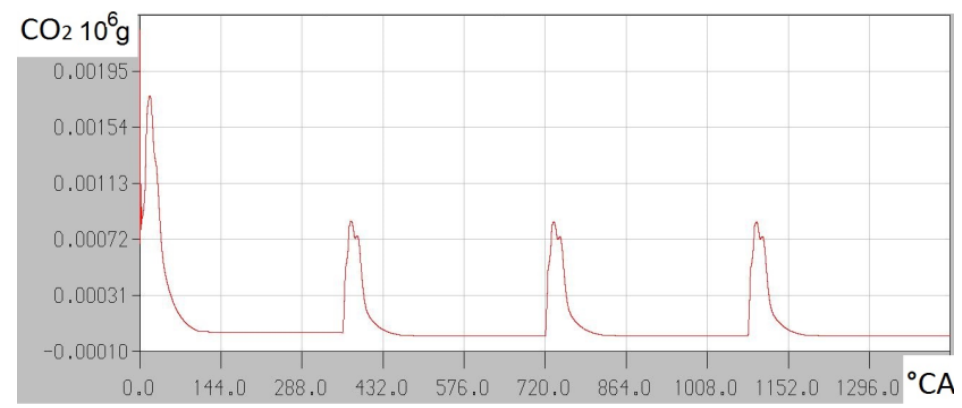

Fig. 24 Change in the amount of carbon dioxide at the variation of the combustion start crank angle of $-0.5^{\circ}$

\subsection{Engine 2}

Table 6 Values achieved in Engine 2 during variations of the start of combustion

\begin{tabular}{|l|c|c|c|c|c|}
\hline Start of combustion $\left({ }^{\circ}\right.$ crank angle) & -1 & $-0,5$ & 0 & 0,5 & 1 \\
\hline Effective power $(\mathrm{kW})$ & 1227,79 & 1229,43 & 1230,85 & 1232,04 & 1232,99 \\
\hline Mean effective pressure (bar) & 17,86 & 17,88 & 17,90 & 17,92 & 17,93 \\
\hline Specific effective consumption (g/kWh) & 169,73 & 169,51 & 169,31 & 169,14 & 169,01 \\
\hline Maximum cylinder pressure (bar) & 159 & 161 & 164 & 166 & 168 \\
\hline
\end{tabular}

Table 7 Deviations of the parameters in Engine 2 during variations of the combustion start angle

\begin{tabular}{|l|c|c|c|c|}
\hline Start of combustion $\left({ }^{\circ}\right.$ crank angle) & -1 & $-0,5$ & 0,5 & 1 \\
\hline Effective power $(\mathrm{kW})$ & $1,8 \%$ & $1,67 \%$ & $1,46 \%$ & $1,38 \%$ \\
\hline Mean effective pressure (bar) & $2,57 \%$ & $2,68 \%$ & $2,9 \%$ & $2,95 \%$ \\
\hline Maximum cylinder pressure (bar) & $6,08 \%$ & $4,9 \%$ & $1,94 \%$ & $0,76 \%$ \\
\hline
\end{tabular}

When the correlations of the combustion start angle and maximum pressures in the cylinder are shown in a diagrammatic way, a linear dependence can be noted:

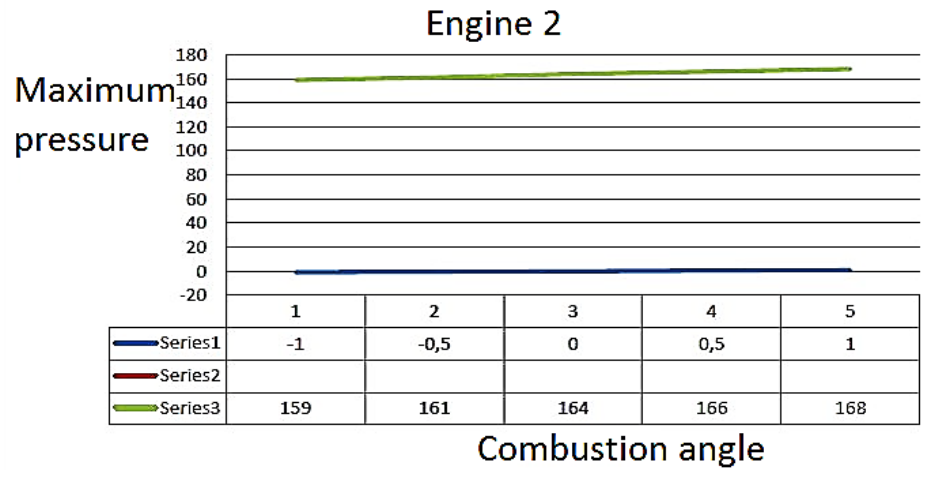

Fig. 25 Dependence of the maximum cylinder pressures (Series 3) on the combustion start (Series 1)

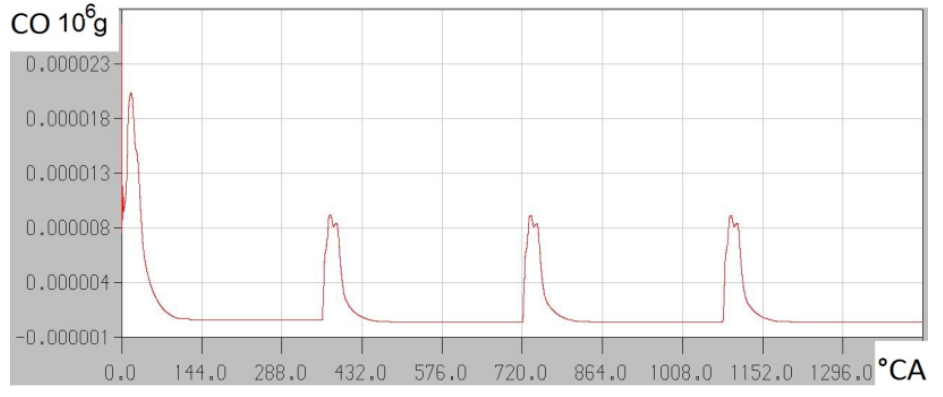

Fig. 26 Change in the amount of carbon monoxide at the combustion start crank angle of $0.5^{\circ}$ 


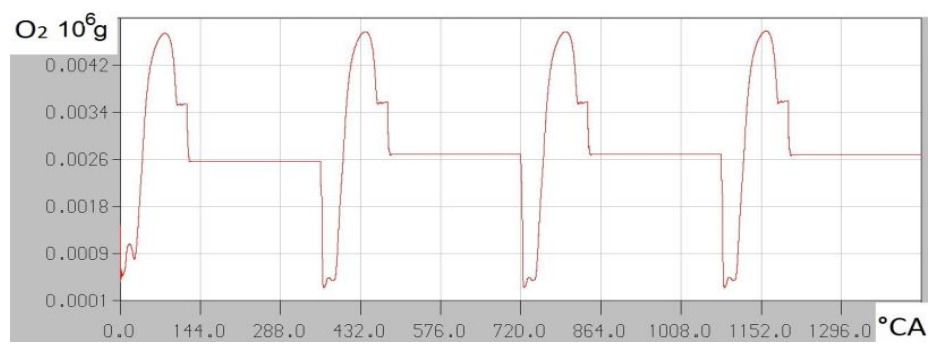

Fig. 27 Oxygen curve at the start of combustion at the crank angle of $0.5^{\circ}$

\subsection{Comparison of the results}

The analysis of the effects of the injection angle variations on the exhaust gases has produced the following results and conclusions:

- At the combustion angle of $-1^{\circ}$, the emission of carbon monoxide is higher in Engine 1 by $0.63 \%$ in the first cycle and by $1 \%$ in the second cycle. Deviations in carbon dioxide in Engine 1 amount to $1.02 \%$ in the first working cycle and $5.46 \%$ in the second cycle, when compared to Engine 2. Oxygen emissions are higher by $1.27 \%$.

- At the combustion angle of $-0.5^{\circ}$, the emission of carbon monoxide is higher in Engine 1 by $0.5 \%$ in the first cycle and by $1 \%$ in the second cycle. Likewise, emission of carbon dioxide in Engine 1 is larger by $0.9 \%$ in the first working cycle and by $7.15 \%$ in the second cycle, when compared to Engine 2. Engine 1 expels $1.55 \%$ more oxygen than Engine 2.

- At the combustion angle of $0.5^{\circ}$, the emission of carbon monoxide is higher in Engine 1 by $0.5 \%$ in the first cycle and by $1 \%$ in the second cycle. Likewise, emission of carbon dioxide in Engine 1 is larger by $0.9 \%$ in the first working cycle and by $7 \%$ in the second cycle, when compared to Engine 2. The deviation of oxygen emission amounts to $1.23 \%$.

- At the combustion angle of $-1^{\circ}$, the emission of carbon monoxide is higher in Engine 1 by $0.5 \%$ in the first cycle and by $1 \%$ in the second cycle. Predictably, emission of carbon dioxide in Engine 1 is higher by $0.7 \%$ in the first working cycle and by $7.3 \%$ in the second cycle, when compared to Engine 2. Oxygen deviation amounts to $1.3 \%$.

\section{Effects of the exhaust valve operation on exhaust emissions}

This chapter discusses the effects of the opening and closing angles of the exhaust valves on exhaust emissions. The opening and closing angles have been found for the valves in which the model's validity has been achieved. The analysis is performed for four angles in total: opening angles of $61^{\circ}$ and $62^{\circ}$, and closing angles of $58^{\circ}$ and $59^{\circ}$. Again, due to identical curves and their typical points, the discussion will include just a pair of graphs.

\subsection{Engine 1}

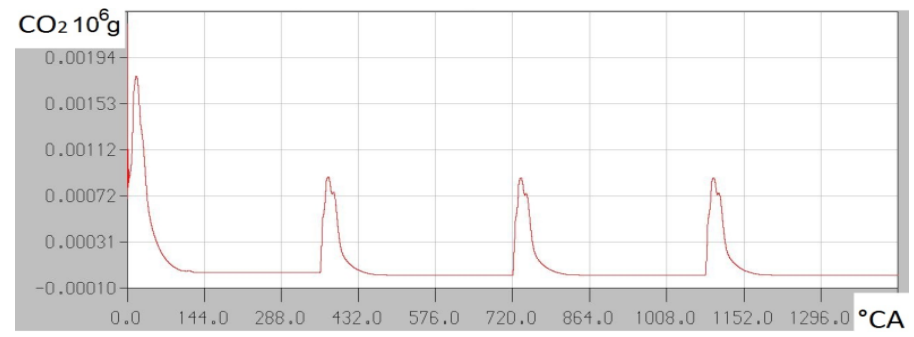

Fig. 28 Emission of carbon dioxide at the exhaust valve opening angle of $61^{\circ}$ and closing angle of $58^{\circ}$ 


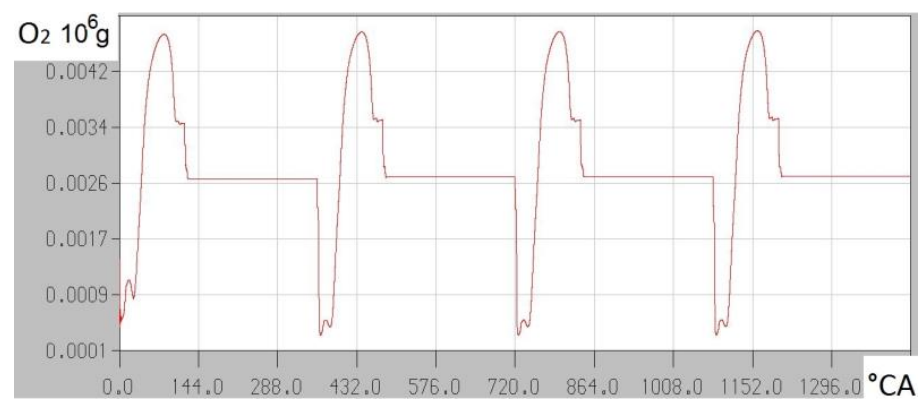

Fig. 29 Emission of oxygen at the exhaust valve opening angle of $61^{\circ}$ and closing angle of $58^{\circ}$

9.2 Engine 2

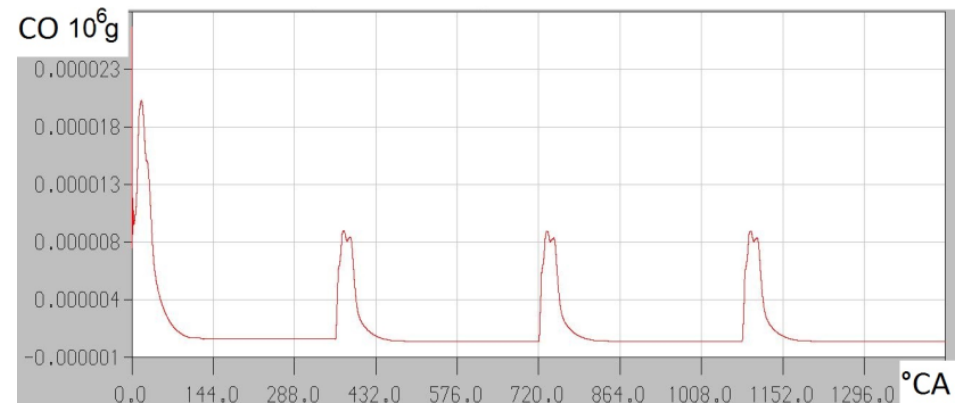

Fig. 30 Emission of carbon monoxide at the exhaust valve opening angle of $62^{\circ}$ and closing angle of $59^{\circ}$

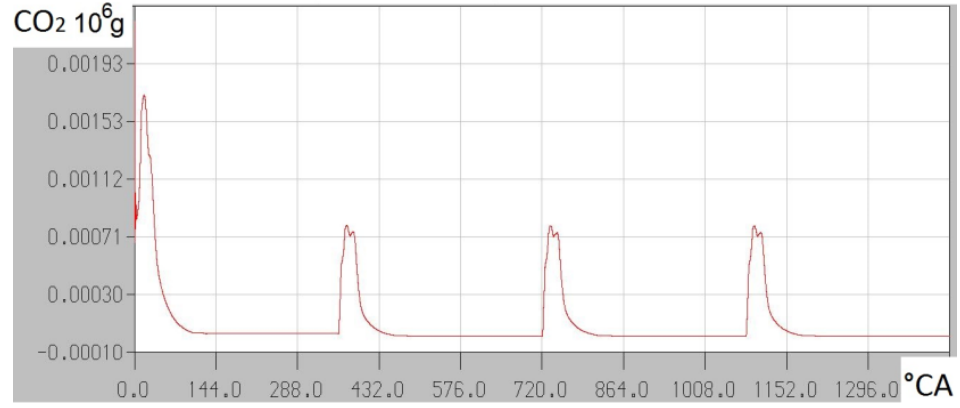

Fig. 31 Emission of carbon dioxide at the exhaust valve opening angle of $62^{\circ}$ and closing angle of $59^{\circ}$

\subsection{Comparisons}

The analysis has produced the following deviations:

- At the opening angle of $61^{\circ}$ and the closing angle of $58 \%$ the emission of carbon dioxide is higher in Engine 1 by $0.62 \%$ in the first cycle and by $7.08 \%$ in the second cycle. Likewise, emission of carbon monoxide in Engine 1 is higher by $1 \%$ and oxygen emission is higher by $1.27 \%$ than in Engine 2 .

- At the opening angle of $62^{\circ}$ and the closing angle of $59 \%$ the emission of carbon dioxide is higher in Engine 1 by $0.75 \%$ in the first cycle and by $7.16 \%$ in the second cycle. Predictably, emission of carbon monoxide in Engine 1 is higher by $1.01 \%$ and oxygen emission is higher by $1.2 \%$ than in Engine 2 .

\section{Conclusion}

Fuel that burns in the cylinder produces exhaust emissions that are harmful to human beings and the environment. Larger cylinder dimensions, as in marine slow-speed two-stroke engines, produce considerable amounts of exhaust emissions that should be controlled when 
designing the engine and during engine operation, in order to remain in line with the international regulations that have been implemented by IMO organisation [12].

Insights into IMO technical documentation on marine slow-speed two-stroke diesel engines have provided data for the same type of engine with different rates of compression and power. A model at a stationary operating point at $100 \%$ load has been produced and the comparison with the results obtained through measurement has been made. The results of exhaust gases, which have been produced at the testbed and by simulation model for the observed engines, are found to be within limits, ranging from $2 \%$ to $7 \%$.

The analysis of the effects of exhaust valve timing, compression rate and combustion angle on exhaust gases has produced results that prove the traceability of deviations between modelled and real designs in the above specified percentages, thus enabling the conclusions useful for further development of the exhaust emission control systems.

\section{REFERENCES}

[1] Medica V., Račić N., Radica G.: „Performance Simulation of Marine Slow-Speed Diesel Propulsion Engine with Turbocharger under Aggravated Conditions“, Strojarstvo, Volume 51, No 3, pp.199-212., Zagreb, 2009.

[2] Heywood John B.: "Internal Combustion Engine Fundamentals", McGraw-Hill Inc., New York, 1988.

[3] Benson, R. S.: The thermodynamics and gas dynamics of internal combustion engines, Oxford, 1986.

[4] Jankov, R., Matematičko modeliranje strujno-termodinamičkih procesa i pogonskih karakteristika dizelmotora, I i II dio, Naučna knjiga Beograd, 1984.

[5] McAllistar, S., Jyh-Yuan Chen, Fernandez-Pello, A. C.: „Fundamentals of Combustion Processes“, Springer Science, Business Media, 2011.

[6] Savva, Nicholas S., Hountalas, Dimitrios T.: „Evolution and application of a pseudo-multi-zone model for the prediction of NOx emissions from large-scale diesel engines at various operating conditions“, Energy Conversion and Management, Greece, 2014.

[7] Lalić, B., Komar, I., Nikolić, D.: „Optimization of Ship Propulsion Diesel Engine to Fulfill the New Requirements for Exhaust Emissions“, Transactions on Maritime Science (ToMS), April 2014, Vol. 3, No. 1.3 (2014), 1 Split, 2014, pp. 20-31, DOI:10.7225/toms.v03.n01.003

[8] Komar, I., Lalić, B.: „Current Air Quality Issue, Chapter 8 - Sea Transport Air Pollution“, InTecH,

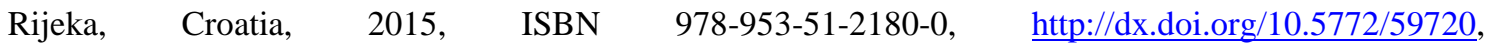
http://dx.doi.org/10.5772/58743

[9] Medica, V.: Simulation of turbocharged diesel engine driving electrical generator under dynamic working conditions, Doctoral Thesis, Rijeka, 1988.

[10] Radica, G.: Expert System for Diagnosis and Optimisation of Marine Diesel Engines, Strojarstvo, 2008, pp.105-116, ISSN 0562-1887.

[11] Račić, N.: Simulacija rada brodskog propulzijskog sustava sa sporohodnim dizelskim motorom u otežanim uvjetima, Doctoral Dissertation, Tehnički fakultet Rijeka, Rijeka, 2008.

[12] Radica, G., Medica, V., Račić, N.: „Development of marine engines to fulfil IMO emission regulations“, International Congress Energy and the Environment 2008, Opatija, pp. 153-164.

\footnotetext{
Submitted: $\quad$ 16.03.2016 Branko Lalić

Faculty of Maritime Studies, Ruđera Boškovića 37, 21000 Split

Accepted: $\quad$ 20.06.2016 Gojmir Radica, gojmir.radica@fesb.hr Faculty of electrical engineering, mechanical engineering and naval architecture Ruđera Boškovića 32, 21000 Split

Nikola Račić,

Faculty of Maritime Studies, Ruđera Boškovića 37, 21000 Split
} 